\title{
The zebrafish bcl-2 homologue Nrz controls development during somitogenesis and gastrulation via apoptosis-dependent and -independent mechanisms
}

\author{
E Arnaud $^{1,4}, \mathrm{KF}$ Ferri $^{1,5}$, J Thibaut ${ }^{1,5}, \mathrm{Z}$ Haftek-Terreau ${ }^{2,6}$, \\ A Aouacheria ${ }^{1,7}$, D Le Guellec ${ }^{2}$, T Lorca $^{3}$ and G Gillet ${ }^{\star, 1}$ \\ 1 Apoptosis and Oncogenesis Laboratory, IBCP, UMR 5086 CNRS-UCBL, IFR \\ 128, Lyon France \\ 2 Extracellular Matrix and Development Laboratory, IBCP, UMR 5086 CNRS- \\ UCBL, IFR 128, Lyon France \\ 3 CRBM, UPR 1086 CNRS, route de Mende, 34293 Montpellier cedex 5, France \\ ${ }^{4}$ Current address: Département de Biochimie, Université de Lausanne, Chemin \\ de Boveresses 155, 1066 Epalinges, Switzerland \\ 5 These authors contributed equally to this work \\ ${ }^{6}$ Current address: Centre Intégratif de Génomique, Université de Lausanne, \\ 1015 Lausanne-Dorigny, Switzerland \\ 7 Current address: Biométrie et Biologie Evolutive, UMR 5558 CNRS-UCB, 43 \\ av du 11 novembre 69622 Villeurbanne cedex, France \\ * Corresponding author: G Gillet, Institut de Biologie et Chimie des Protéines, 7 \\ passage du Vercors, 69367 Lyon cedex 07, France. \\ Tel: 334727226 58; Fax: 3347226 01; E-mail: g.gillet@ibcp.fr
}

Received 04.4.05; revised 09.9.05; accepted 20.9.05; published online 11.11.05 Edited by $\mathrm{A}$ Villunger

\begin{abstract}
Although the role of the b-cell lymphoma (Bcl)-2 family of apoptosis inhibitors is well documented in tumor cells and tissue morphogenesis, their role during the early development of vertebrates is unknown. Here, we characterize $\mathrm{Nrz}$, a new Bcl-2-related inhibitor of apoptosis in zebrafish. Nrz is a mitochondrial protein, antagonizing the death-accelerator Bax. The $n r z$ gene is mainly expressed during gastrulation and somitogenesis. The knockdown of $n r z$ with antisense morpholinos leads to alterations of the somites, correlated with an increase in apoptosis. In addition, earlier during development, in the zebrafish gastrula, nrz knockdown results in an increase of snail-1 expression at the margin and frequent gastrulation arrest at the shield stage, independently of apoptosis. Together these data suggest that Nrz, in addition to its effect on apoptosis, contributes to cell movements during gastrulation by negatively regulating the expression of Snail-1, a transcription factor that controls cell adhesion.

Cell Death and Differentiation (2006) 13, 1128-1137. doi:10.1038/sj.cdd.4401797; published online 11 November 2005
\end{abstract}

Keywords: apoptosis; Bcl-2; gastrulation; Nr-13; somites; zebrafish

Abbreviations: $\mathrm{BCL}$, b-cell lymphoma; $\mathrm{BH}-3$, bcl-2 homology domain 3; DMEM, Dulbecco's minimal essential medium; EMT, epithelial mesenchymal transition; E-YSL, external yolk syncitial layer; FITC, fluoresceine isothiocyanate; HPF, hours post fertilization; HVT, herpes virus of turkeys; I-YSL, internal yolk syncitial layer; MO, morpholino; NR-13, neuroretina clone 13; ORF, open reading frame; PBS, phosphate buffer saline; PCD, programmed cell death; RT-PCR, reverse transcriptase-polymerase chain reaction; TGF, transforming growth factor; TM, transmembrane domain; YSL, yolk syncitial layer

\section{Introduction}

Space and time-dependent control of programmed cell death (PCD) is essential for cell homeostasis in metazoans. Studies in nematode, drosophila and mouse have underscored the role of PCD in development. ${ }^{1,2}$ In humans, deregulation of $P C D$ is observed in degenerative diseases and cancer. Regulators of PCD are thus promising targets for drug discovery. ${ }^{3}$ The b-cell lymphoma $(\mathrm{Bcl})-2$ family of proteins is critical for the control of PCD. ${ }^{4}$ These proteins control the release of cytochrome $c$ from the mitochondria, a key step in apoptosis, the most documented type of PCD. ${ }^{4}$ Into the cell, they interact together, forming homo- or heterodimers; the relative concentrations of these complexes is critical for cell survival or death.

Interactions between Bcl-2 family members occur via conserved regions. ${ }^{5}$ Chemicals mimicking these interaction domains are used as decoy ligands to selectively inhibit the formation of such complexes. ${ }^{6}$ A number of these are being tested in preclinical or clinical trials. ${ }^{3}$ However, all the interactions involving $\mathrm{Bcl}-2$ family members are far from being characterized. Indeed, in addition to apoptosis, the Bcl2 family plays numerous roles, for example, cell cycle control, genomic stability, cell signalling. ${ }^{7}$

In vivo model systems are essential to study the various roles of this fascinating family of proteins in vertebrates. Among them, the zebrafish offers a number of advantages, for example, rapid development, transparency of the embryo, genetic accessibility. The apoptosis machinery in the zebrafish is very similar to mammals. ${ }^{8}$ In addition, the zebrafish develops a number of pathologies resembling human diseases, and is used for drug discovery projects. ${ }^{9}$

We present the characterization of $n r z$, the zebrafish homologue of the chicken gene $n r-13$, a $b c /$-2-related gene involved in neoplastic transformation. ${ }^{10}$ In the embryo, the knockdown of $n r z$ leads to an increase of apoptosis and affects somitogenesis. We also show here that, during gastrulation, the Nrz protein has apoptosis-independent effects and that the downregulation of Nrz activates the expression of Snail-1, a transcription factor controlling the expression of cell adhesion molecules. ${ }^{11}$ 


\section{Results and Discussion}

\section{Molecular cloning of $\boldsymbol{n r z}$}

Zebrafish EST clone \# AW076878 exhibited the closest homology with the chicken antiapoptotic gene $n r-13$. The $n r z$ gene exhibits one single intron at the same position as chicken $n r-13$ and herpes virus (HVT) vnr-13 (see Supplementary data $\mathrm{S} 1$ ). This new gene was called $n r z$, for $n r-13$ zebrafish.

The putative zebrafish protein deduced from the cDNA sequence exhibited the four typical Bcl-2 homology domains and the $\mathrm{C}$-terminal hydrophobic tail, which characterize most apoptosis inhibitors. The sequence of the Nrz protein is highly homologous to chicken and HVT Nr-13 - 39.7 and $38.7 \%$ identity, respectively (Figure 1), which identifies $n r z$ as the orthologue of chicken $n r-13$. In contrast, the homology is significantly lower with the mammalian $n r-13$ orthologues, namely human $n r h / b c l-b,{ }^{12,13}$ and mouse diva/boo. ${ }^{14,15}$ This suggests that in mammals the $n r-13$ gene did evolve rapidly and may have acquired other functions, compared to egglaying species.

\section{Antiapoptotic activity of $\mathrm{Nrz}$}

The activity of the Nrz protein was evaluated in vitro. In Xenopus eggs extracts, Nrz was shown to delay caspase activation, acting as a Bax inhibitor (Figure 2a). This result was confirmed using transient transfections. As shown in Figure 2b, Nrz prevented cell death following serum withdrawal in Cos-7 cells. Taken together, these results show that $\mathrm{Nrz}$ is an apoptosis inhibitor and is presumably an antagonist of Bax.

A typical feature of $\mathrm{Bcl}-2$-like proteins is their ability to interact with the outer mitochondrial membrane. ${ }^{16}$ Confocal microscopy analyses showed that Nrz is actually localized into the mitochondria, as $\mathrm{Nr}-13$ itself and related apoptosis inhibitors (Figure 2c). Together, these results indicate that $\mathrm{Nrz}$ is a bona fide apoptosis inhibitor, acting at the mitochondrial level.

\section{Expression of $\boldsymbol{n} r \boldsymbol{z}$ during development}

We examined $n r z$ expression pattern during the development of the zebrafish by quantitative reverse transcriptasepolymerase chain reaction (RT-PCR). The results in Figure $3 a$ show that the $n r z$ transcript is present at $5 \mathrm{~h}$ post fertilization (hpf), corresponding to $50 \%$ epiboly. The $n r z$ transcript is still present at $8 \mathrm{hpf}(80 \%$ epiboly). At later stages, expression of $n r z$ was mainly detected during late somitogenesis (20 hpf). Nrz expression was further analysed by whole mount in situ hybridization. In contrast to the sense riboprobe, which gave no signal (not shown), the antisense probe allowed to detect the $n r z$ transcript. Zygotic expression was observed at 5-8 hpf, confirming RT-PCR data. During this period, corresponding to gastrulation and epiboly, the cells of the blastoderm move vegetally over the surface of the yolk to envelop it completely. After the cells have covered about half of the yolk (50\% epiboly), an involution process occurs throughout the margin of the epibolizing blastoderm, cells turning inward and moving back along the outer cell sheets. Remarkably, the $n r z$ transcript was detected at the level of the yolk syncitial layer (YSL), mainly into the external YSL, close to the margin (Figure 3b, $5 \mathrm{hpf}$ ). A typical ring shape labelling is observed as the margin gets closer to the vegetal pole (Figure 3b, 8-10 hpf). At $18 \mathrm{hpf}$, that is, during myotome differentiation, nrz labelling was mainly detected in the somites, and to a lesser extent in the telencephalon (Figure 3b, 18hpf). Later on, $n r z$ labelling gradually disappeared (not shown).
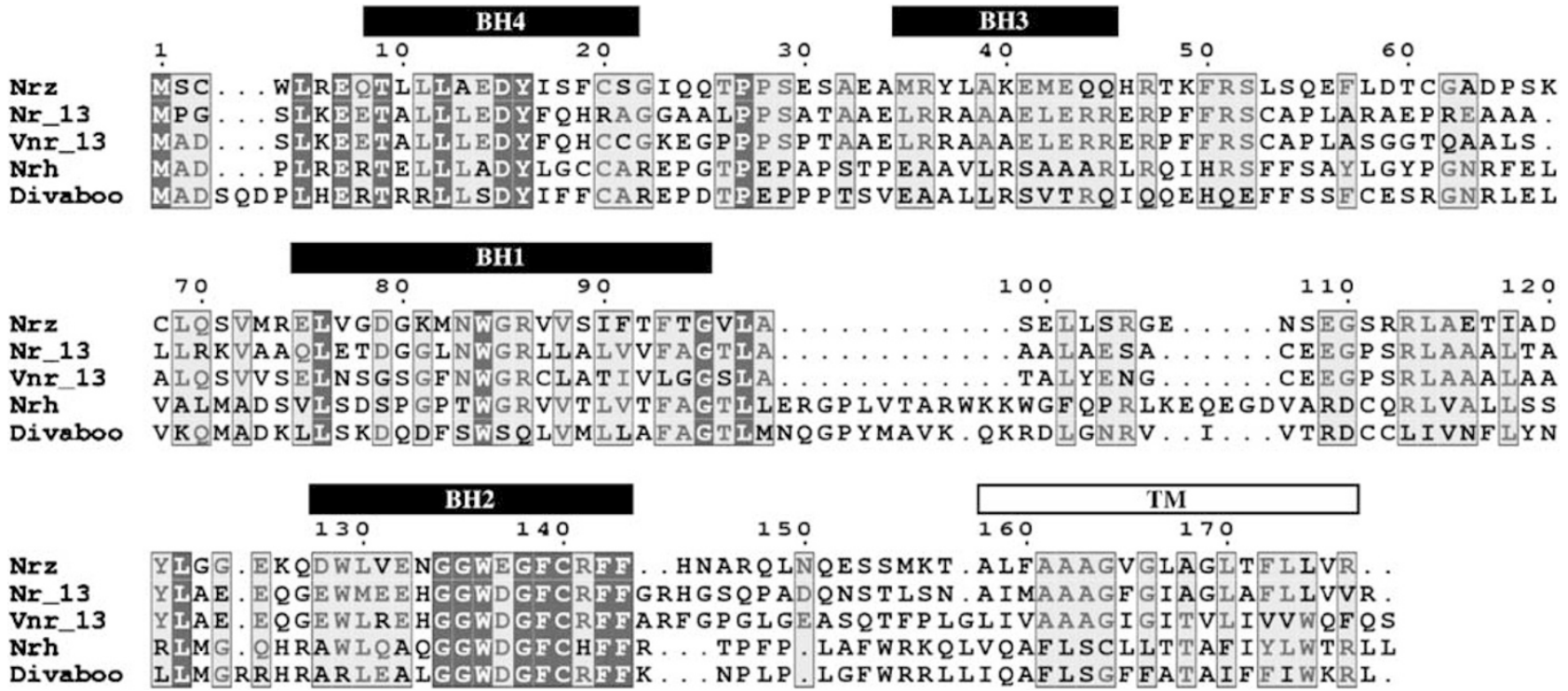

Figure 1 Sequence of the Nrz protein. Alignment of Nrz with chick Nr-13 (AAK54806), HVT vNr-13 (AY756568), human Nrh (AJ458330) and mouse Diva/Boo (AAC83150). Identical and similar amino acids are boxed in dark and light grey, respectively. Positions of BH domains and of the C-terminal hydrophobic domain (TM) are shown 

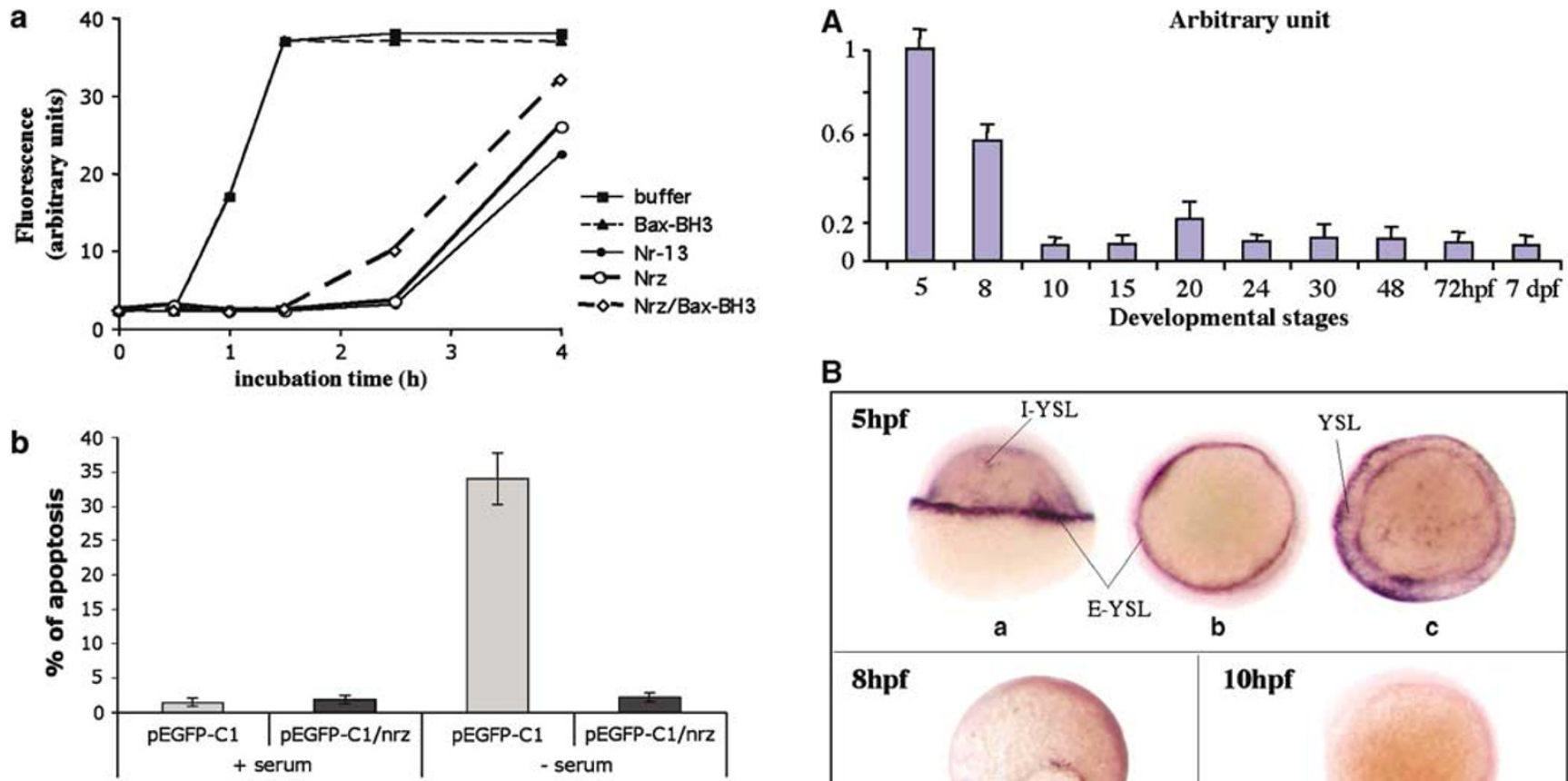

C

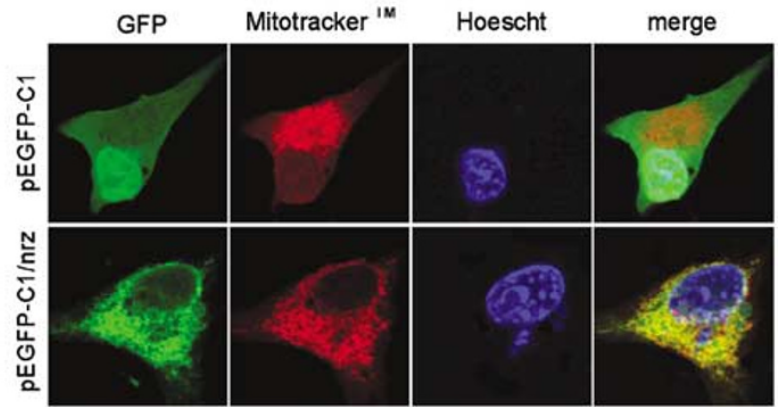

Figure 2 Antiapoptotic activity and subcellular localization of $\mathrm{Nrz}$. (a) Inhibition of caspase activation. Xenopus eggs extracts were incubated in the presence of buffer alone, $\mathrm{BH} 3-\mathrm{Bax}$ peptide (corresponding to the $\mathrm{BH} 3$ domain of $\mathrm{Bax}$ ), chicken Nr-13, zebrafish Nrz either alone or with BH3-Bax. At the indicated times, caspase activity was measured by fluorimetry. $\mathrm{Nrz}$ and $\mathrm{Nr}-13$ both inhibit caspase activity. $\mathrm{Nrz}$ is an inhibitor of $\mathrm{BH} 3-\mathrm{Bax}$. Representative results of three independent experiments. (b) Nrz inhibits cell death in vertebrate cells. Cos-7 cells were transfected either by the empty vector (pEGFP-C1) or the recombinant vector (pEGFP-C1/nrz), expressing GFP and GFP-Nrz fusion protein, respectively. Cells were grown for $48 \mathrm{~h}$ with $(+)$ or without $(-)$ serum. Percentage of apoptotic cells was estimated by counting pycnotic nuclei in transfected cells (GFP positive), using a fluorescence microscope. Results of two independent experiments carried out in triplicate; standard error of the mean is shown. (c) Nrz is a mitochondrial protein. Analysis of Nrz subcellular localization by confocal microscopy. Cos-7 cells were transiently transfected with pEGFP-C1 or $\mathrm{pEGFP}-\mathrm{C} 1 / \mathrm{nrz}$ expressing GFP or GFP-Nrz fusion protein, respectively. Mitochondria and nuclei were visualized using Mitotracker ${ }^{\mathrm{TM}}$ Red and Hoechst 33258 , respectively. In contrast to GFP, the GFP-Nrz protein colocalizes with Mitotracker $^{\mathrm{TM}}$

\section{Nrz regulates apoptosis during somitogenesis}

The role of $n r z$ during development was further analysed using antisense oligonucleotides (morpholinos, MOs) designed to knockdown the expression of $n r z$ at the translational level. Fluoresceine isothiocyanate (FITC)-labelled morpholinos were injected at the 1-4 cell stage and were found homogeneously distributed in the whole embryo at least for $48 \mathrm{~h}$ (Figure 4a). Two morpholinos were used: $n r z-\mathrm{MO}$

B

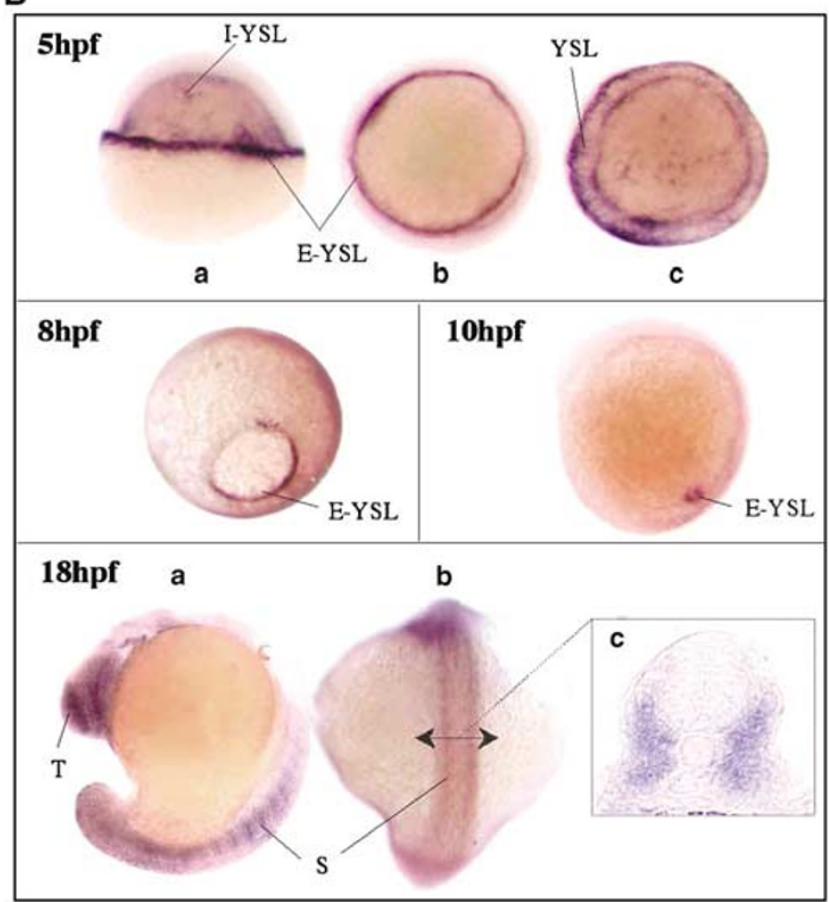

Figure $3 n r z$ expression in the embryo. (a) Quantitative RT-PCR. Histograms represent signal intensity ratio (arbitrary units) between Nrz and histone H2A, used for calibration. Experiment performed on total RNAs prepared from whole embryos. Results of two independent experiments carried out in triplicate. Standard error of the mean is shown. (b) Whole mount in situ hybridization. At the $50 \%$ epiboly stage ( $5 \mathrm{hpf}$ ), $n r z$ is expressed in the yolk syncytial layer (YSL); (a) side view, showing expression in both the internal YSL (I-YSL) and the external YSL (E-YSL); (b) vegetal view, showing expression in the I-YSL; (c) animal view. Expression in the E-YSL is maintained throughout the whole epiboly process (8-10 hpf). Later on (18 hpf, a, b), nrz expression is detected in the somites (S) and the telencephalon (T). Cross-section shows $n r z$ transcript in the myotome (18 hpf, c)

antisense, hybridizing at the vicinity of the AUG codon (see Supplementary data S1) and 4mis-MO negative control. As shown in Figure 4a, embryos injected with $4 \mathrm{mis}-\mathrm{MO}$ behaved like noninjected embryos. In contrast, most embryos injected with the antisense (morphants) exibited major defects, particularly in the caudal region, as shown at $24 \mathrm{hpf}$ (Figure 4a, nrz-MO), see Table 1 (line 3: nrz-MO $250 \mu \mathrm{M}$ ). In addition, morphants exhibited a high rate of mortality, $35 \%$ of the embryos dying before $10 \mathrm{hpf}(n=247)$ when the $n r z-\mathrm{MO}$ morpholino was used at a concentration of $250 \mu \mathrm{M}$; mortality increased in a dose-dependent manner, reaching $85 \%$ at $1 \mathrm{mM} n r z-\mathrm{MO}(n=230)$, see Table 1. Remarkably, injection of $n r z-M O$ in the YSL (where the $n r z$ transcript is found) at $2.5 \mathrm{hpf}$ 
(256 cells stage) significantly increased early mortality $(51 \%$ at $250 \mu \mathrm{M}, n=55)$. In contrast, 4 mis-MO had no effect $(5 \%$ mortality, $n=149$ ). Phenotype specificity of the morphants was confirmed by coinjecting the in vitro transcribed $n r z$ mRNA together with nrz-MO. In these conditions, the phenotype of the injected embryos (95\% normal, $n=117$ ) was the same as noninjected embryos (Figure 4a, nrz$\mathrm{MO}+n r z \mathrm{mRNA})$. Coinjection of an unrelated mRNA did not rescue the phenotype of the morphants (35\% mortality, $n=50)$. We also checked the effect of injecting nrz mRNA alone: most corresponding embryos developed normally ( $85 \%$ normal, $n=300$ ), However, early mortality was slightly increased (15\%), compared to noninjected embryos $(5 \%)$, indicating that the overexpression of $n r z$ might affect early development to some extent. Quantitative data are displayed in Table 1.

We directly evaluated the effect of $n r z-\mathrm{MO}$ on the amount of $\mathrm{Nrz}$ protein by Western blotting on whole embryo protein extracts. To this end, a rabbit polyclonal antibody was raised against the purified recombinant Nrz protein. As shown in Figure 4b, nrz-MO downregulated $\mathrm{Nrz}$ protein level, in contrast to 4mis-MO; coinjection of nrz mRNA, which maintained the $\mathrm{Nrz}$ concentration at normal levels, prevented the effect of $n r z-\mathrm{MO}$.

a
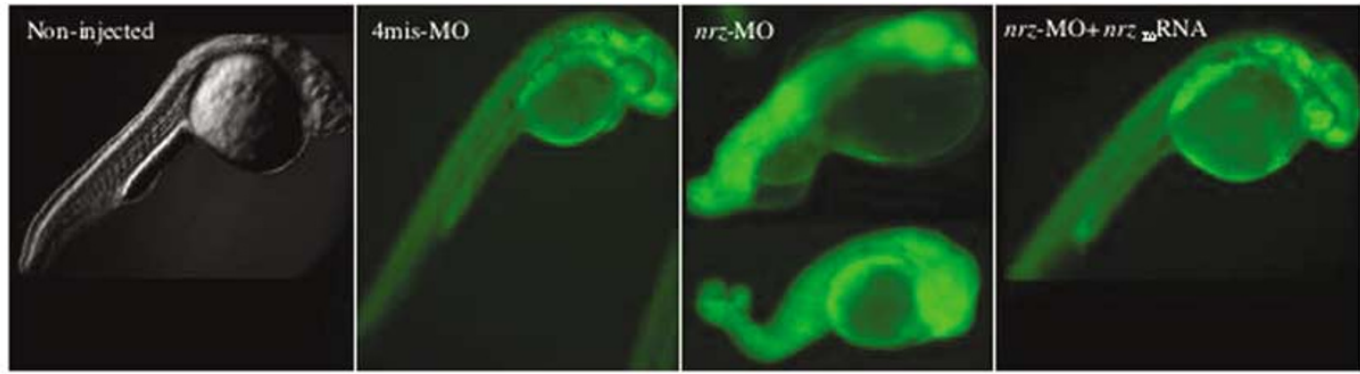

b

exposure time : $15 \mathrm{~min}$
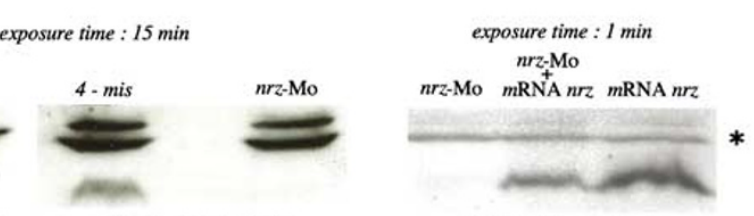

polyclonal Ab anti-Nrz

polyclonal Ab anti-Nrz
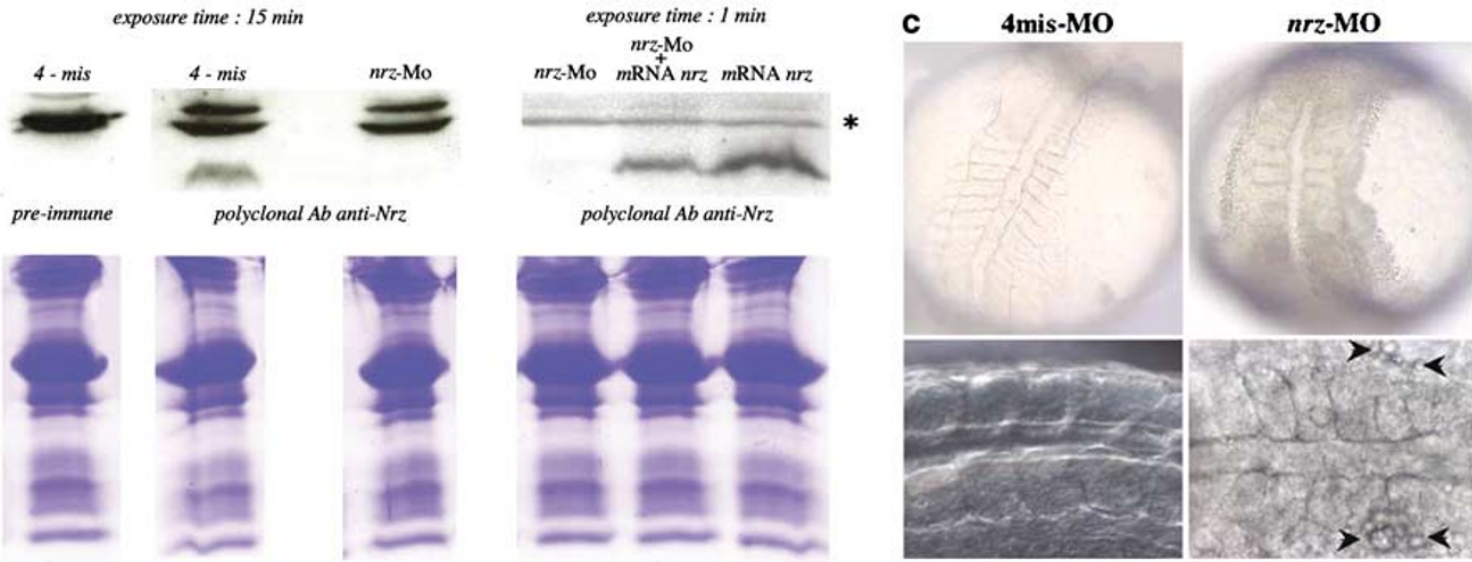

d 4mis-MO

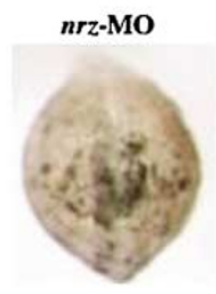

myoD
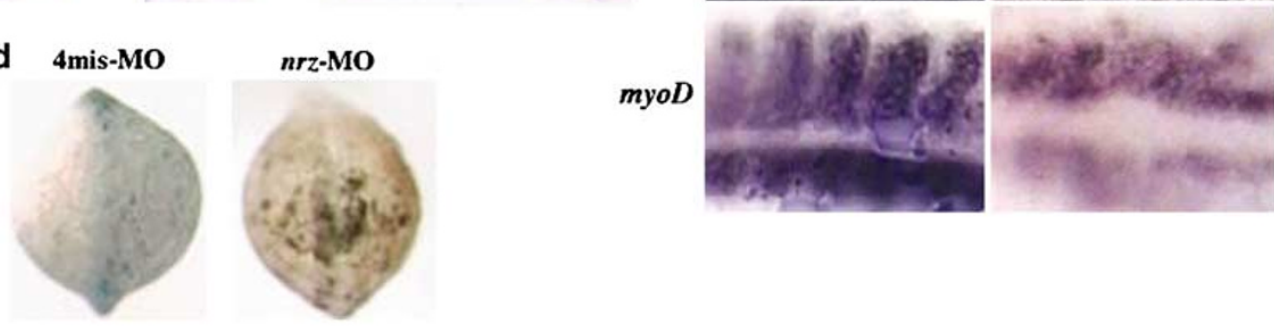

e
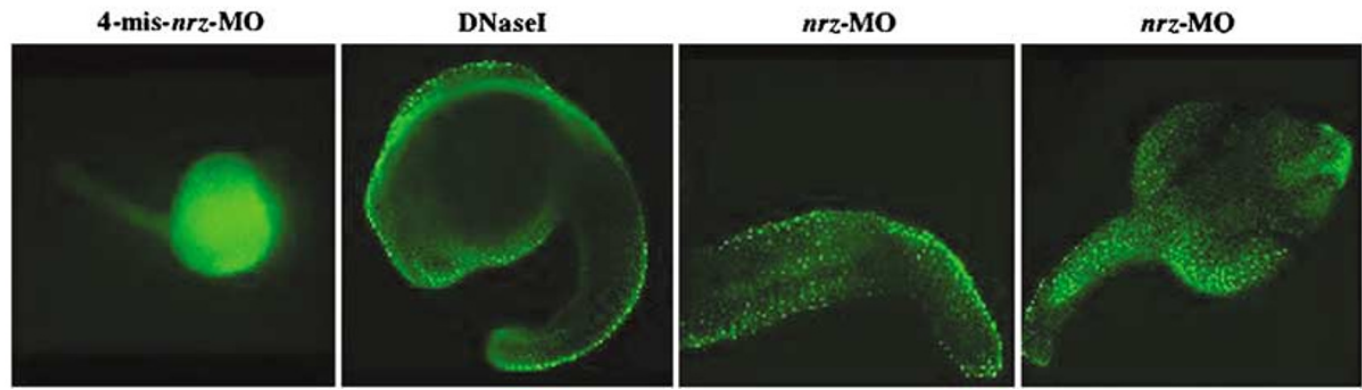

Figure 4 
These results confirmed that the phenotype of the morphants resulted from the knockdown of nrz. In these embryos, the somites were profoundly disorganized, with irregular boundaries and altered expression of $\mathrm{MyoD}$, a key transcription factor in muscle differentiation, Figure 4c. Moreover, a number of cells of abnormal morphology accumulated, suggesting that there might have been an increase in cell death in the morphants. Indeed, a large number of TUNEL-positive cells are detected in the morphants, compared to control embryos (Figure 4d and e). Thus, in morphant embryos, the observed disorganization of the somites is correlated with increase of cell death. Of note, cell death is not only detected in the somites but also in other areas, including the head (Figure 4e). This suggests that the control of apoptosis by Nrz might be crucial in a number of tissues during somitogenesis.

\section{Nrz controls gastrulation independently of apoptosis}

In addition to its effect on somitogenesis, we showed that $n r z$ knockdown resulted in a significant increase in early mortality (up to $80 \%$, depending on the concentration of the morpholino, compared to $5 \%$ for control embryos, see above and Table 1). Together with the fact that $n r z$ was highly expressed during epiboly (Figure 3 ), this suggested that $n r z$ might also play a role before the onset of somitogenesis. Figure 5 shows the typical behaviour of one morphant during the first $30 \mathrm{~min}$ following the shield stage (6 hpf). Whereas in normal embryos blastoderm cells continued to extend towards the vegetal pole (see Figure $3 b$ ), this progression was stopped in a significant number of morphants at the shield stage (up to $80 \%$ ), see

Table 1 Effect of morpholinos on early development of zebrafish embryos

\begin{tabular}{|c|c|c|c|c|}
\hline Injections & $\begin{array}{l}\text { Number of } \\
\text { embryos ( } n)\end{array}$ & $\begin{array}{l}\text { Phenotypes ( } 50 \% \\
\text { epiboly) }\end{array}$ & $\begin{array}{c}\text { Early mortality } \\
\text { (10 hpf) (\%) }\end{array}$ & Phenotypes (16-24 hpf) \\
\hline Noninjected & 200 & $100 \%$ normal & 5 & $95 \%$ normal \\
\hline $4 \mathrm{mis}-\mathrm{MO}$ & 149 & $100 \%$ normal & 5 & $95 \%$ normal \\
\hline$n r z-\mathrm{MO}(250 \mu \mathrm{M})$ & 247 & $30 \%$ gastrulation arrest & 35 & $98 \%$ abnormal somites \\
\hline$n r z-\mathrm{MO}(333 \mu \mathrm{M})$ & 640 & $50 \%$ gastrulation arrest & 55 & \\
\hline$n r z-M O(1 \mathrm{mM})$ & 230 & $80 \%$ gastrulation arrest & 85 & \\
\hline$n r z-M O(250 \mu \mathrm{M})+Z-V A D . f m k$ & 35 & $29 \%$ gastrulation arrest & 35 & $92 \%$ normal \\
\hline$n r z-\mathrm{MO}(250 \mu \mathrm{M})+b a x-\mathrm{MO}(250 \mu \mathrm{M})$ & 64 & $30 \%$ gastrulation arrest & & \\
\hline$n r z-\mathrm{MO}(250 \mu \mathrm{M})+n r-13$ mRNA & 117 & $100 \%$ normal & 5 & \\
\hline nrz-MO $(250 \mu \mathrm{M})+$ nonrelevant mRNA & 50 & $30 \%$ gastrulation arrest & 35 & \\
\hline nrz mRNA & 300 & $85 \%$ normal & 15 & $90 \%$ normal \\
\hline$n r z-\mathrm{MO}(250 \mu \mathrm{M})+$ snail-1-MO-1 & 227 & $98 \%$ normal & 7 & \\
\hline nrz-MO $(333 \mu \mathrm{M})+$ snail-1-MO-2 & 300 & $82 \%$ normal & & \\
\hline nrz-MO $(333 \mu \mathrm{M})+5$ mis-snail-1-MO-2 & 280 & $36 \%$ gastrulation arrest & & \\
\hline snail-1-MO-1 & 48 & $98 \%$ normal & 5 & \\
\hline snail-1-MO-2 & 150 & $100 \%$ normal & 5 & \\
\hline$n r z-\mathrm{MO}(250 \mu \mathrm{M}$ at $2.5 \mathrm{hpf})$ & 55 & $51 \%$ gastrulation arrest & 56 & \\
\hline$n r z-\mathrm{MO}(333 \mu \mathrm{M}$ at $2.5 \mathrm{hpf})$ & 250 & $62 \%$ gastrulation arrest & 67 & \\
\hline$n r z-\mathrm{MO}(250 \mu \mathrm{M}$ at $2.5 \mathrm{hpf})+$ snail-1-MO-1 (1-4 cell) & 350 & $100 \%$ normal & 5 & \\
\hline$n r z-\mathrm{MO}(333 \mu \mathrm{M}$ at $2.5 \mathrm{hpf})+$ snail-1-MO-1 (1-4 cell) & 250 & $100 \%$ normal & 5 & \\
\hline$n r z-\mathrm{MO}(333 \mu \mathrm{M}$ at $2.5 \mathrm{hpf})+$ snail-1-MO-2 (1-4 cell) & 180 & $77 \%$ normal & 82 & \\
\hline$n r z-\mathrm{MO}(333 \mu \mathrm{M}$ at $2.5 \mathrm{hpf})+5 \mathrm{mis}-$ snail-1-MO-2 (1-4 cell) & 130 & $50 \%$ gastrulation arrest & 55 & \\
\hline snail-1 mRNA & 295 & $40 \%$ gastrulation arrest & 45 & \\
\hline
\end{tabular}

Injections performed at the 1-4 cell stage, except if otherwise indicated. Concentration of injected morpholinos was $1 \mathrm{mM}$, except when otherwise indicated (brackets). In vitro transcribed mRNAs were all used at $100 \mathrm{ng} / \mu \mathrm{l}$. To assess specificity, two snail-1 antisense morpholinos were used (snail-1-MO-1 and -2) as well as a negative control with five mismatches (5mis-snail-1-MO-2)

\footnotetext{
Figure 4 Effect of knockdown of $n r z$ on somitogenesis. (a) Detection of FITC-labelled morpholinos in 24 hpf zebrafish embryos. Injected embryos are fluorescent. Noninjected embryo is shown (left panel). Embryos injected with the negative control 4 mis-MO are normal (middle left panel). In contrast, embryos injected with the antisense morpholino nrz-MO are disorganized in the caudal region (middle right panel). Coinjection of the nrz mRNA together with nrz-MO restores wild-type phenotype (right panel). (b) Detection of the Nrz protein. Whole protein extracts from zebrafish embryos ( 5 hpf) were analysed by Western blot using the polyclonal anti-Nrz antibody or the preimmune serum. Negative control (4mis), antisense ( $n r z-M O)$, antisense together with in vitro synthetized nrz mRNA (nrz-MO + mRNA nrz), in vitro transcribed $n r z$ mRNA alone (mRNA nrz). Top: a signal is detected at $16 \mathrm{kDa}$ with the anti-Nrz antibody, but not by the preimmune serum, corresponding to the predicted molecular weight of the Nrz protein. This band disappears upon injection of $n r z-M o$. Overexposure of the Western blot (left lanes: exposure time 15 min) reveals a nonspecific band at $26 \mathrm{kDa}$ (star), which is detected both by the preimmune serum and the anti-Nrz antibody. Embryos injected with the in vitro transcribed nrz mRNA accumulate large amounts of the Nrz protein (right lanes, exposure time $1 \mathrm{~min}$ ). In these experiments, the nonspecific signal at $26 \mathrm{kDa}$ is used as an internal loading control. Bottom: Coomassie blue staining of the protein samples electrophoresed in parallel on a second gel in exactly the same conditions, for quality control. (c) Phenotype of injected embryos 16 hpf. Somites are disorganized in embryos injected with the antisense (nrz-MO), but not with the negative control (4mis-MO). Top panels, low magnification; middle panels, high magnification (Nomarski); bottom panel, detection of myoD expression (in situ hybridization). Injection of nrz-MO results in the appearance of apoptotic cells (upper and middle right panels, arrows). Somite boundaries are irregular (middle right), myoD expression pattern is drastically altered (bottom right). (d) Effect of nrz knockdown on cell death at $16 \mathrm{hpf}$. Cell death was detected by TUNEL assay at 16 hpf. Pictures were taken after completion of the peroxidase reaction. Embryos were injected with the negative control (4mis-MO, left panel) or the antisense (nrz-MO, right panel). The nrz-MO-injected embryo is TUNEL positive. (e). Effect of $n r z$ knockdown on cell death at $23 \mathrm{hpf}$. Cell death was detected by TUNEL assay at $23 \mathrm{hpf}$. In this case, embryos were observed under the fluorescent microscope to directly detect incorporated FITC-labelled nucleotides. Embryos injected with nrz-MO (bottom), but not the 4mis negative control (top, right) are fluorescent and thus TUNEL positive. Whole morphant embryo is shown (right). Tail is shown at higher magnification on the next panel (middle right). Side view of positive control is shown (DNAse l-treated embryo, middle left). In this experiment, the negative control is overexposed, a nonspecific signal is observed into the vitellus (left)
} 


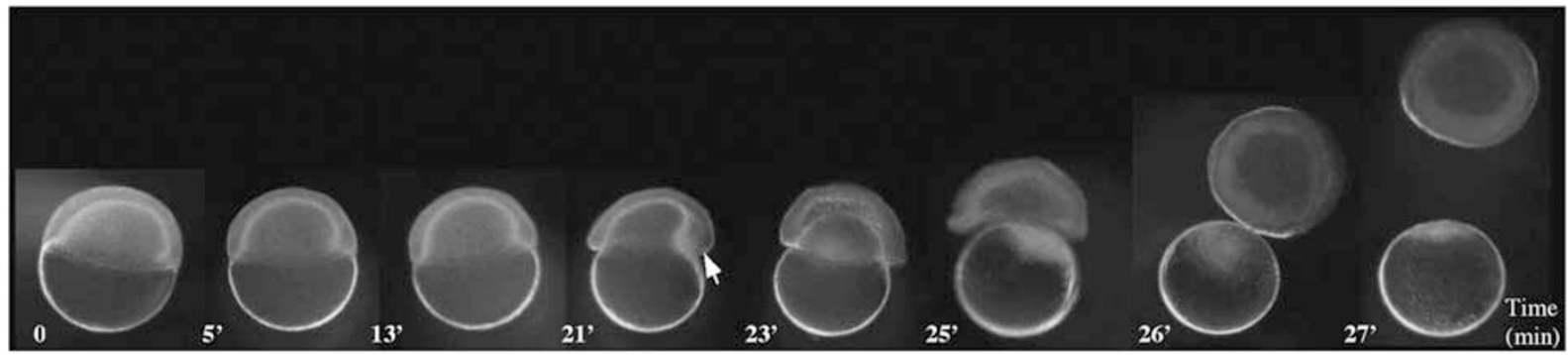

Figure 5 Effect of the knockdown of $n r z$ on gastrulation. Video time lapse analysis of morphant embryos. The video sequence shown starts at the $50 \%$ epiboly stage (time 0). Progression of the margin is arrested $(0-13 \mathrm{~min})$. Cells begin to detach in the area of the shield (21 min, arrow). Cells of the hypoblast detach from the YSL (23-25 min). The embryo falls apart (26-27 min)

Table 1. Then, constriction of the embryo appeared at the margin. Cells at the margin eventually detached from the yolk in the shield area, and the entire embryo detached from the yolk within a few minutes. No such phenotype was observed with control embryos, indicating that this splitting off was actually due to nrz knockdown (Table 1). Although at this stage the apoptosis machinery did not yet seem to be in operation, ${ }^{17}$ we could not absolutely exclude that the knockdown of $n r z$ would prematurely activate apoptosis, resulting in premature arrest of gastrulation. Actually, as shown in Figure $6 a$, we found no increase of the number of TUNELpositive cells in embryos injected with $n r z-\mathrm{MO}$. In addition, we analysed whether apoptosis inhibitors acting downstream of $n r z$ could rescue the 'gastrulation arrest' phenotype. First, we used the pan caspase inhibitor ZVAD-fmk, which efficiently inhibits caspase activation in vivo in the zebrafish embryo not shown, see also Ikegami et al. ${ }^{17}$ Regarding the effect of ZVAD-fmk on early mortality ( $10 \mathrm{hpf})$, which is a direct result of this premature gastrulation arrest, Figure $6 \mathrm{~b}$ shows that early mortality was not significantly affected by ZVAD-fmk in embryos injected with nrz-MO. Second, together with nrz$\mathrm{MO}$, we coinjected an antisense morpholino directed against the apoptosis accelerator Bax, which also failed to prevent the epiboly arrest due to $n r z$ knockdown (Table 1). Together, these results strongly suggested that the effect of $n r z$ knockdown on gastrulation is apoptosis independent. In contrast, ZVAD-fmk fully restores normal development of surviving morphants during somitogenesis (92\% normal, see Table 1), confirming that, at these latter stages, the knockdown of $n r z$ activates caspase-dependent cell death.

\section{Nrz controls gastrulation via a Snail-1-dependent pathway}

If not due to apoptosis, the cells may have detached as a consequence of modifications to their adhesion properties. Indeed, during gastrulation, important changes in cell adhesion and migration occur, some being collectively referred to as the epithelial-mesenchymal transition (EMT). The transcription factor Snail-1 regulates the expression of major adhesion proteins during gastrulation. ${ }^{18}$ We thus analysed the expression of snail-1 by in situ hybridization in embryos expressing or not the Nrz protein. Remarkably, as shown in Figure $7 \mathrm{a}$, the expression level of snail-1, which is restricted to a
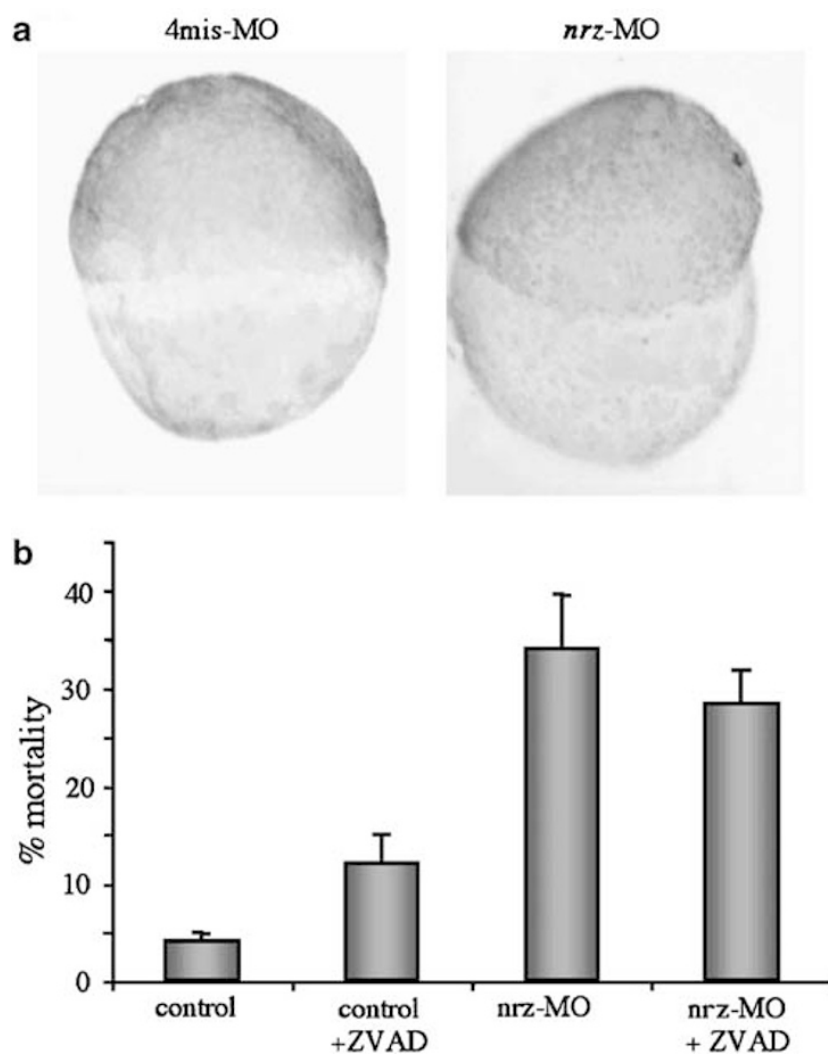

Figure 6 Apoptosis-independent effect of $n r z$ knockdown on gastrulation. (a) Detection of cell death (shield stage). Embryos injected with negative control (4mis-MO) and antisense morpholino (nrz-MO) are both TUNEL negative. (b) Early mortality due to $n r z$ knockdown is caspase independent. Injected embryos (with 4mis-MO or $n r z-M O$ ) were treated or not by ZVAD. Histograms represent percentage of mortality at $10 \mathrm{hpf}$. Results of three independent experiments carried out in duplicate. Standard error of the mean is shown

the margin, is significantly increased in the embryos injected with nrz-MO. These data were confirmed by quantitative RTPCR. This suggested that snail-1 is negatively regulated by Nrz. If snail-1 acts downstream of $n r z$, one possibility could be that the overexpression of snail-1 might lead to the same phenotype as nrz knockdown. Thus, the in vitro transcribed snail-1 mRNA was injected into the embryos at the 1-4 cell stage and its effect on gastrulation was analysed. Figure $7 \mathrm{~b}$ 

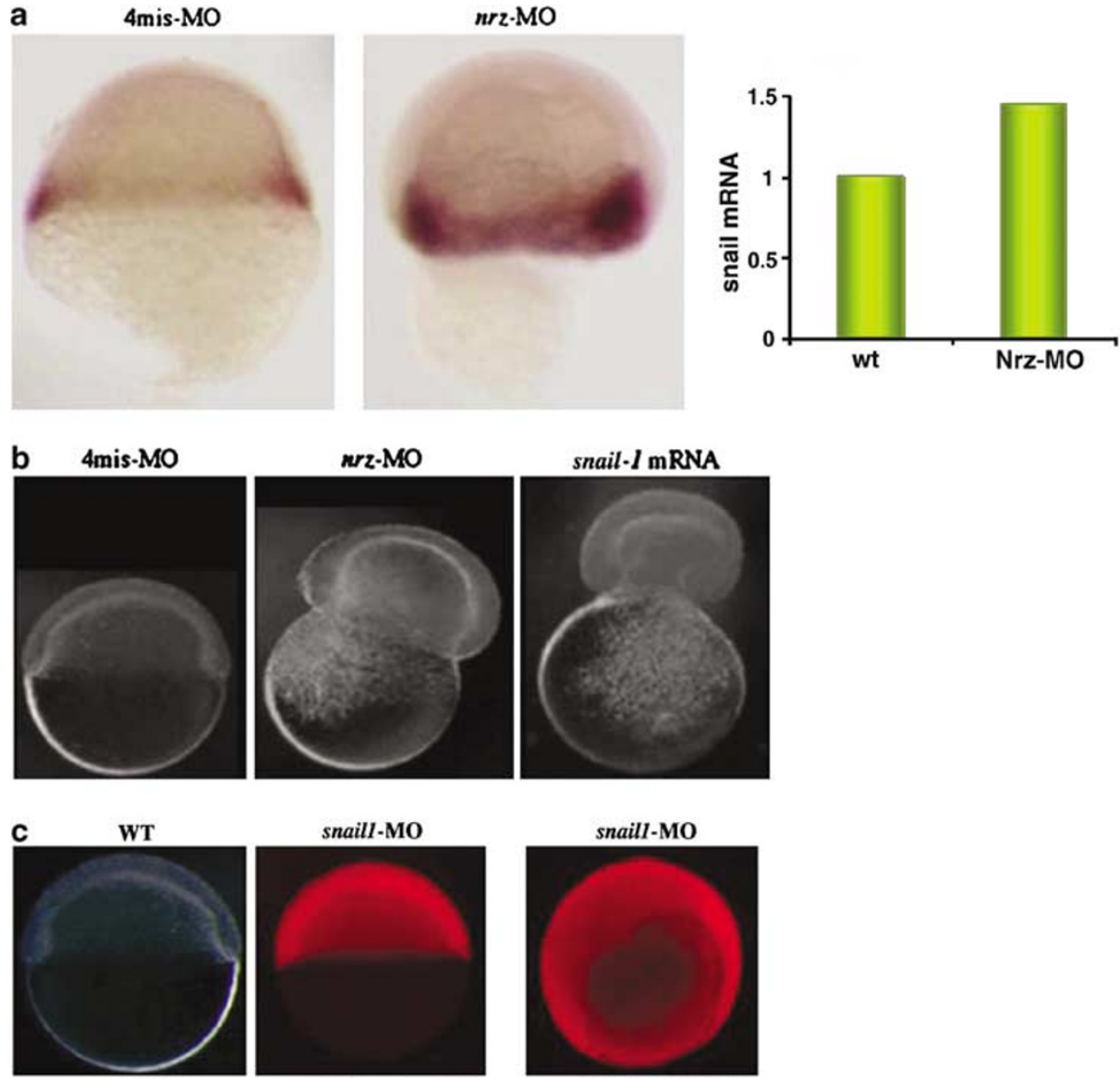

snaill-MO

snaill-MO
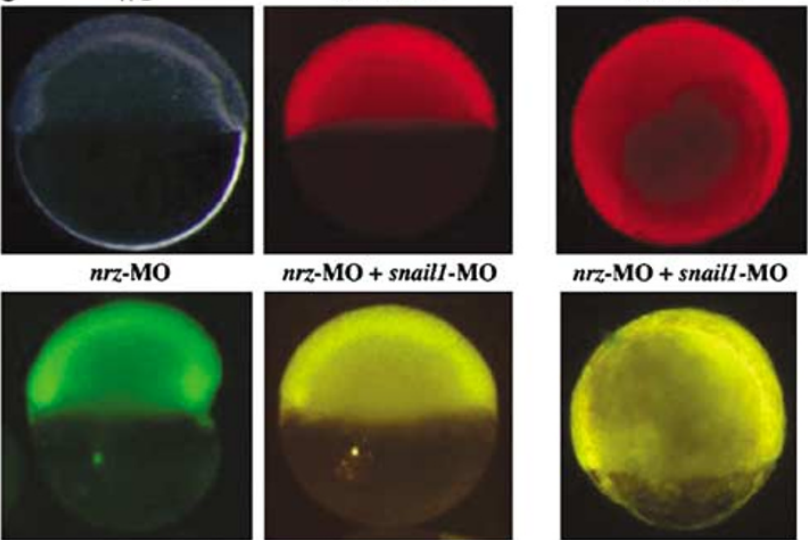

nrz-MO late

nrz-MO + snaill-MO

nrz-MO + snaill-MO

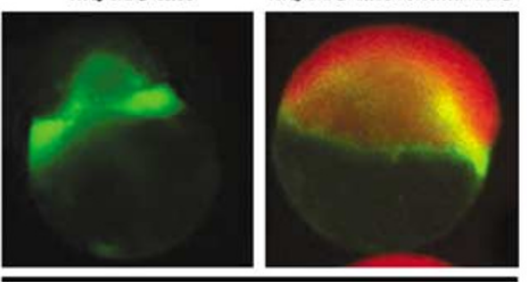

$50 \%$ epiboly

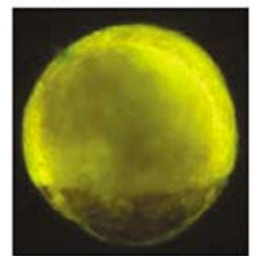

nrz-MO late
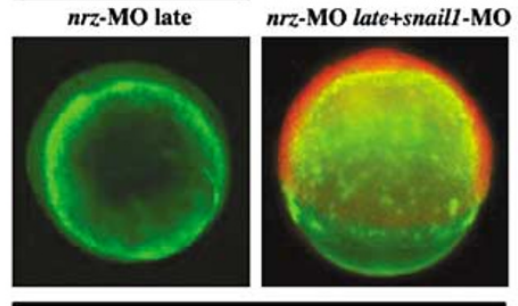

$80 \%$ epiboly

Figure 7 Interplay between Nrz and Snail-1 during gastrulation. (a) nrz knockdown increases the expression level of snail-1 in the margin. Embryos were observed at $6 \mathrm{hpf}$. Left panels: whole mount in situ analysis of snail-1 expression in embryos injected with the negative control (4mis-MO) or antisense morpholino (nrz-MO). Right panel: quantitative RT PCR analysis of total snail mRNA amount in zebrafish extracts (arbitrary units). wt: noninjected embyos; nrz-MO: embryos injected with the antisense morpholino, representative result of three independent experiments. (b) The ectopic expression of snail-1 mimics the phenotype of nrz knockdown. Embryos (1-4 cell stage) were injected with the negative control (4mis-MO, left panel), the antisense morpholino (nrz-MO, middle panel) or the in vitro synthetized snail-1 mRNA (right). Embryos shown in the middle and right panels are similar. Time lapse video recording of an sna1 morphant is shown as Supplementary data (S2). (c) Down regulation of snail-1 rescues the gastrulation arrest phenotype. Embryos are observed at $50 \%$ epiboly (left) and $80 \%$ epiboly (right) and injected either at $1-4$ cell stage (upper panels 'snail1-MO' and middle panels) or at the 256 cells stage (bottom panels). Upper left panel, noninjected embryo (wt). Middle left panel, embryos injected with the nrz-MO antisense morpholino exhibit abnormal gastrulation. Whereas snail-1 antisense sna1-MO has no effect (upper panels 'snail1-MO'), coinjection of sna1$\mathrm{MO}$ together with $\mathrm{nrz-MO}$ restores normal gastrulation (middle panels ' $\mathrm{nrz}-\mathrm{MO}$ + snail1-MO'). Nrz-MO and sna1-MO are labelled in green and red, respectively; embryos injected with both morpholinos at 1-4 cell stage appear in yellow (middle panels). Direct injection of $n r z-\mathrm{MO}$ (green) in the YSL also results in premature gastrulation arrest (bottom panels ' $n r z-M O$ late'), which is fully prevented by first injecting sna1-MO (red) in the animal pole at 1-4 cells stage (bottom panels, ' $n r z-M O$ late + snail1MO') 
shows that the overexpression of snail-1 mimics the effect of the nrz-MO antisense morpholino (40\% 'gastulation arrest' phenotype, $n=295)$, indicating that snail-1 may actually mediate the effect of $n r z$ on cell adhesion during gastrulation. This hypothesis was confirmed by the fact that the knockdown of snail-1 by coinjecting a sna1-MO antisense (referred to as snail-1-MO-1 in Table 1) together with nrz-MO rescued the gastrulation arrest phenotype observed at $6 \mathrm{hpf}$ (98\% normal, $n=227$ ), (Figure 7c, Table 1). Coinjection of another sna1$\mathrm{MO}$ antisense (referred to as snail-1-MO-2 in Table 1) had the same effect ( $82 \%$ normal, $n=300$ ), while the corresponding negative control 5mis-snail-1-MO-2 did not prevent the gastrulation arrest due to the knockdown of $n r z \quad(36 \%$ gastrulation arrest, $n=280$ ), see Table 1 .

During epiboly, snail-1 is expressed in involuting cells of the germ ring at the margin of the blastoderm. ${ }^{19,20}$ In contrast, according to our in situ hybridization data, the $n r z$ transcript is present in the external YSL, at the vicinity of the germ ring. This suggests that Nrz may regulate snail-1 gene expression non-cell-autonomously. Indeed, direct injection of $n r z-\mathrm{MO}$ into the YSL at the 256 cells stage results in premature gastrulation arrest, which is prevented by first injecting snail1-MO-1 or snail-1-MO-2, but not 5mis-snail-1-MO-2, at the 1-4 cell stage (Figure 7c, Table 1 ).

Thus, Nrz may control the release of inductive signals from the YSL which would in turn act on transduction pathways regulating snail-1 expression in the embryo, such as those controlled by Notch or transforming growth factor (TGF) $\beta$, two activators of snail expression and promoters of EMT as well. ${ }^{21,22}$ However, on the basis of the result presented here, one cannot exclude that $n r z$ knockdown might also affect gastrulation in a cell autonomous way, having direct effects in the YSL, which would in turn compromise adhesion between the yolk and the blastoderm. Indeed cell movements during gastrulation closely depend on cytoskeleton dynamics, which must be controlled very precisely. ${ }^{23}$ Actually, Bcl-2 itself might indirectly control microtubule dynamics via an Erk-dependent pathway, at least in certain cells. ${ }^{24}$ In addition, there is evidence for direct interactions between Bcl-2 family members and proteins of the cytoskeleton, or scaffold proteins, such as paxillin. ${ }^{25}$ Indeed, the $\mathrm{Bcl}-2$ family appears to participate to multiple signalling pathways into the cell, independently of the apoptosis. ${ }^{26}$ This raises the possibility that Nrz may act on gastrulation via both non-cell and cell-autonomous mechanisms.

A number of genes involved in cell-cell or cell-matrix interactions, such as E-cadherin, ${ }^{27}$ fibronectin, ${ }^{18}$ collagen type $11,{ }^{28}$ appear to be regulated by the Snail family of transcription factors. Some of them regulate cell movements during early embryogenesis. ${ }^{29}$ These genes are potential targets of Bcl-2 family members, including Nrz. Actually, Ecadherin and collagen type II were reported to be regulated by $\mathrm{Bcl}-2$, the canonical apoptosis inhibitor. ${ }^{30,31}$ Moreover, the knockdown of E-cadherin strongly affects early development in the zebrafish. ${ }^{32}$ However, the knockdown of $n r z$ does not seem to affect the expression of E-cadherin in the zebrafish gastrula (results not shown), whereas paraxial protocadherin, another adhesion molecule having a role during gastrulation, ${ }^{33}$ is upregulated upon $n r z$ knockdown (see Supplemental data S3). Thus, although the underlying molecular mechanisms remain to be determined, this report supports the idea that, during development, cell movements and adhesion may be controlled by Bcl-2 family members, at least in part via snail-dependent pathways, independently of apoptosis.

\section{Materials and Methods}

\section{Zebrafish}

Zebrafish (a cross between $A B$ and Tübingen) were maintained under standard laboratory conditions. ${ }^{34}$ For some experiments, ZVAD was added in the culture medium ( $300 \mu \mathrm{M}$ final concentration) as described. ${ }^{35}$

\section{Nrz cloning}

Databases were screened with chicken Nr-13 using tblastn. The AW076878 clone encoding a complete open reading frame (ORF) was selected. The cDNA (531 bp) corresponding to zebrafish $n r-13$ homologue (called $n r z$ ) was subcloned into pGEMT by PCR and entirely resequenced. Multialignments were performed with Clustal W and ESPript 2.2 softwares.

\section{Nrz protein and antibody production}

$\mathrm{Nrz}$ protein (residues 1-157), produced in BL-21(DE3) and purified as described previously, ${ }^{36}$ was used for polyclonal antibody production (Valbex, Villeurbanne). The rabbit antiserum was purified as described. ${ }^{10}$

\section{Caspase inhibition assay}

Caspase inhibition assays in Xenopus egg extracts were performed as described. ${ }^{36}$ Briefly, Xenopus egg extracts were incubated with purified recombinant proteins $\mathrm{Nrz}$ or $\mathrm{Nr}-13$, the latter used as a control, with or without the BH3-Bax peptide. At different time points, aliquots were incubated for $10 \mathrm{~min}$ with $50 \mu \mathrm{M}$ Ac-DEVD-AMC (Calbiochem). The reaction was stopped with cold phosphate buffer saline (PBS); cleavage of the caspase substrate Ac-DEVD-AMC was monitored with an FLX-800T (Bio-Teck) fluorimeter (excitation $380 \mathrm{~nm}$, emission $460 \mathrm{~nm}$ ).

\section{Cell death assay in Cos-7 cells}

$\mathrm{Nrz}$ cDNA was subcloned into the Xhol and Sall sites of pEGFP$\mathrm{C} 1$ (Clontech). Cos-7 cells were grown at $37^{\circ} \mathrm{C}, 5 \% \mathrm{CO}_{2}$ in Dulbecco's minimal essential medium (DMEM) medium supplemented with $10 \%$ foetal bovine serum. At 30\% confluence, cells were transfected with pEGFP-C1-nrz using Fugene 6 reagent as indicated by the manufacturers (Roche). At $14 \mathrm{~h}$ after transfection, the media were replaced by DMEM without serum. At $48 \mathrm{~h}$ after serum withdrawal, the percentage of transfected cells displaying pycnotic nuclei was measured using Hoechst 33258 fluorescent dye.

\section{Confocal microscopy}

Cells were incubated with Mitotracker ${ }^{\mathrm{TM}}$ (Molecular Probes) to visualize mitochondria as described. ${ }^{37}$ After four washes in PBS, cells were fixed with $4 \%$ paraformaldehyde for $20 \mathrm{~min}$ at room temperature and incubated $30 \mathrm{~min}$ with $5 \mu \mathrm{g} / \mathrm{ml}$ Hoechst 33258 to visualize nuclei. Cells were observed under a Leica TCS-SP2 confocal microscope.

\section{Quantitative RT-PCR}

Total RNA was extracted at different stages. Embryos were frozen in liquid nitrogen and homogenized in lysis buffer (4 M GIT, $25 \mathrm{mM}$ sodium citrate, 
$0.5 \%$ sarcosin, $1 \% \quad \beta$-mercapto-ethanol) and extracted with phenolchloroform. The aqueous phase was precipitated with 2 volumes of ethanol and $1 / 10$ volume of $3 \mathrm{M} \mathrm{Na}$-acetate $\mathrm{pH} 5.3$ and then purified by centrifugation in a $\mathrm{CsCl}$ gradient. Purified RNA was treated with RNasefree DNase, extracted with phenol-chloroform and resuspended in DEPCtreated water for reverse transcription.

Quantitative PCR were performed in triplicate using the Quantitect SYBR Green PCR kit (Qiagen) on an iCycler iQ (Biorad), using gene-specific primers for $n r z$ (forward $5^{\prime}$ AGCAGGAGTGGGTT TAGCTGGT; reverse 5' CAGCGCTGGGGAAAAACAGTG), sna-1 (forward 5' ACCTGCTCTCGCACCTTTAGT; reverse $5^{\prime}$ TGATGCGT CATCCTTCTCCTG), and histone $2 A$ (forward $5^{\prime}$ CCTCGAGCTG GCCGGGAA; reverse 5' CTCGGACTAGCTGCGTTT), the latter being used for calibration.

\section{Western blots}

Total proteins were extracted from liquid nitrogen frozen embryos in RIPA buffer (1\% NP-40, 0.5\% deoxycholic acid, $0.1 \%$ SDS in PBS) containing protease inhibitor cocktail (Roche). After protein concentration determination (Bradford's reagent), samples were loaded on 15\% acrylamide gels. Protein A-purified anti-Nrz antibody was used at 1/300 dilution.

\section{In situ hybridization}

nrz ORF was subcloned into the Xhol-Spel sites of the $\mathrm{pBIISK}{ }^{+}$vector to synthetize sense and antisense digoxygenin-labelled riboprobes. The snail-1 probe was synthetized using the Snail-1/pB-SK ${ }^{+}$vector, ${ }^{19}$ a gift from B Thisse. The papc probe was provided by A Yamamoto. ${ }^{33}$ In situ hybridizations were performed as described. ${ }^{19}$

\section{TUNEL assays}

Embryos were fixed in $4 \%$ paraformaldehyde in PBS $4 \mathrm{~h}$ at room temperature, washed twice in PBS-tween $0.1 \%$ and stored in methanol at $-20^{\circ} \mathrm{C}$, following progressive dehydratation. Assays were performed using in situ cell death detection kit (POD, Roche) as described by the manufacturers. Cell death was detected either using the peroxidase reaction or by directly detecting the incorporated FITC-labelled nucleotides using a fluorescent microscope.

\section{Morpholino and mRNA microinjection}

Morpholinos were designed according to the manufacturer's recommendations (Gene Tools): nrz-MO 5' CATTTTCCTCCCAGCGATGTCAGAC hybridizes with nrz mRNA from position -22 to +3 relative to the start codon (see Supplementary data S1). We used the same sequence with four mismatches (underlined) as negative control: 4mis-MO $5^{\prime}$ CATTATCCTGCCAGCCATGTGAGAC. Except when TUNEL assays were subsequently carried out on injected embryos, morpholinos were labelled with fluorescein.

Other morpholinos: Bax antisense: bax-MO $5^{\prime}$ CCACCC GACGGCGCTGCCATATTAG. Snail-1 antisense-1: sna1-M0-1 $5^{\prime}$ AT CAGTCCACTCCAGTTACTTTCAG (labelled with rhodamine). Snail-1 antisense-2: sna1-MO-2 5' GTCCACTCCAGTTACTTTCAGGGAT. Negative control (mismatches underlined): 5mis-snail-1 MO-2: $5^{\prime}$ GTCGAGTCCACTTAGTTTCACGGAT-3'.

Morpholinos were injected (5-10 $\mathrm{nL})$ into $1-4$ cell stage embryos at concentrations between 0.25 and $1 \mathrm{mM}$ in Danieau buffer $(58 \mathrm{mM} \mathrm{NaCl}$, $0.7 \mathrm{mM} \mathrm{KCl}, 0.4 \mathrm{mM} \mathrm{MgSO}_{4}, 0.6 \mathrm{mM} \mathrm{Ca}\left(\mathrm{NO}_{3}\right)_{2}, 5 \mathrm{mM}$ Hepes $\left.\mathrm{pH} 7.6\right)$.
$\mathrm{Nrz}$ and snail-1 ORFs were subcloned into the $\mathrm{pCS}_{2}^{+}$vector for in vitro transcription (SP6 mMESSAGE mMACHINE ${ }^{\mathrm{TM}}$ kit, Ambion). After Not1 linearization, reaction was performed using $1 \mu \mathrm{g}$ of plasmid template as indicated by the manufacturers. RNAs were microinjected at a concentration of $100 \mathrm{ng} / \mu \mathrm{l}$ in nuclease-free water.

\section{Acknowledgements}

Many thanks to $L$ Bernard for organizing the zebrafish facilities. We thank J Gouttenoire, F Mallein-Gerin and P Blader for help and comments. B Thisse and A Yamamoto are acknowledged for zebrafish probes. This work was supported by Retina France, the ARC, the région Rhône-Alpes and the CNRS. EA was supported by the Ligue nationale contre le cancer (comité de Haute Savoie). AA was supported by the CNRS and the FRM. KFF was supported by the région Rhône-Alpes and EMBO.

\section{References}

1. Hengartner MO (1999) Programmed cell death in the nematode C. elegans. Recent Prog. Horm. Res. 54: 213-222

2. Ranger AM, Malynn BA and Korsmeyer SJ (2001) Mouse models of cell death. Nat. Genet. 28: 113-118

3. Reed JC (2003) Apoptosis-targeted therapies for cancer. Cancer Cell 3: 17-22

4. Scorrano $L$ and Korsmeyer SJ (2003) Mechanisms of cytochrome $c$ release by proapoptotic BCL-2 family members. Biochem. Biophys. Res. Commun. 304: 437-444

5. Gross A, McDonnell JM and Korsmeyer SJ (1999) BCL-2 family members and the mitochondria in apoptosis. Genes Dev. 13: 1899-1911

6. Moreau C, Cartron PF, Hunt A, Meflah K, Green DR, Evan G, Vallette FM and Juin $P$ (2003) Minimal BH3 peptides promote cell death by antagonizing antiapoptotic proteins. J. Biol. Chem. 278: 19426-19435

7. Bonnefoy-Berard N, Aouacheria A, Verschelde C, Quemeneur L, Marcais A and Marvel J (2004) Control of proliferation by Bcl-2 family members. Biochim. Biophys. Acta 1644: 159-168

8. Inohara N and Nunez $\mathrm{G}(2000)$ Genes with homology to mammalian apoptosis regulators identified in zebrafish. Cell Death Differ. 7: 509-510

9. Pichler FB, Laurenson S, Williams LC, Dodd A, Copp BR and Love DR (2003) Chemical discovery and global gene expression analysis in zebrafish. Nat. Biotechnol. 21: 879-883

10. Gillet G, Guerin M, Trembleau A and Brun G (1995) A Bcl-2-related gene is activated in avian cells transformed by the Rous sarcoma virus. EMBO J. 14: 1372-1381

11. Locascio A, Manzanares M, Blanco MJ and Nieto MA (2002) Modularity and reshuffling of Snail and Slug expression during vertebrate evolution. Proc. Natl. Acad. Sci. USA 99: 16841-16846

12. Aouacheria A, Arnaud E, Venet S, Lalle P, Gouy M, Rigal D and Gillet G (2001) $\mathrm{Nrh}$, a human homologue of $\mathrm{Nr}-13$ associates with $\mathrm{Bcl}-\mathrm{Xs}$ and is an inhibitor of apoptosis. Oncogene 20: 5846-5855

13. Ke N, Godzik A and Reed JC (2001) Bcl-B, a novel Bcl-2 family member that differentially binds and regulates Bax and Bak. J. Biol. Chem. 276: 1248112484

14. Inohara N, Gourley T, Carrio R, Muniz M, Merino J, Garcia I, Koseki T, Hu Y, Chen S and Nunez G (1998) Diva, a Bcl-2 homologue that binds directly to Apaf-1 and induces BH3-independent cell death. J. Biol. Chem. 273: 3247932486

15. Song Q, Kuang Y, Dixit VM and Vincenz C (1999) Boo, a novel negative regulator of cell death, interacts with Apaf-1. EMBO J. 18: 167-178

16. Green DR and Kroemer G (2004) The pathophysiology of mitochondrial cell death. Science 305: 626-629

17. Ikegami R, Hunter P and Yager TD (1999) Developmental activation of the capability to undergo checkpoint-induced apoptosis in the early zebrafish embryo. Dev. Biol. 209: 409-433

18. Nieto MA (2002) The snail superfamily of zinc-finger transcription factors. Nat. Rev. Mol. Cell Biol. 3: 155-166 
19. Thisse C, Thisse B, Schilling TF and Postlethwait JH (1993) Structure of the zebrafish snail1 gene and its expression in wild-type, spadetail and no tail mutant embryos. Development 119: 1203-1215

20. Hammerschmidt M and Nusslein-Volhard C (1993) The expression of a zebrafish gene homologous to Drosophila snail suggests a conserved function in invertebrate and vertebrate gastrulation. Development 119: 1107-1118

21. Timmerman LA, Grego-Bessa J, Raya A, Bertran E, Perez-Pommares JM, Diez $\mathrm{J}$, Aranda S, Palomo S, McCormick F, Izpisua-Belmonte JC and de la Pompa $\mathrm{JL}$ (2004) Notch promotes epithelial-mesenchymal transition during cardiac development and oncogenic transformation. Genes Dev. 18: 99-115

22. Peinado H, Quintanilla $M$ and Cano A (2003) Transforming growth factor beta-1 induces snail transcription factor in epithelial cell lines: mechanisms for epithelial mesenchymal transitions. J. Biol. Chem. 278: 21113-21123

23. Solnica-Krezel L and Driever W (1994) Microtubule arrays of the zebrafish yolk cell: organization and function during epiboly. Development 120: 2443-2455

24. Jiao J, Huang X, Feit-Leithman RA, Neve RL, Snider W, Dartt DA and Chen DF (2005) Bcl-2 enhances $\mathrm{Ca}(2+)$ signaling to support the intrinsic regenerative capacity of CNS axons. EMBO J. 24: 1068-1078

25. Sorenson CM (2004) Interaction of bcl-2 with Paxillin through its $\mathrm{BH} 4$ domain is important during ureteric bud branching. J. Biol. Chem. 279: 11368-11374

26. Reed JC (1998) Bcl-2 family proteins. Oncogene 17: 3225-3236

27. Hemavathy K, Ashraf SI and Ip YT (2000) Snail/slug family of repressors: slowly going into the fast lane of development and cancer. Gene 257: 1-12

28. Seki K, Fujimori T, Savagner P, Hata A, Aikawa T, Ogata N, Nabeshima $Y$ and Kaechoong $L$ (2003) Mouse Snail family transcription repressors regulate chondrocyte, extracellular matrix, type II collagen and aggrecan. J. Biol. Chem. 278: 41862-41870
29. Ettensohn CA (1999) Cell movements in the sea urchin embryo. Curr. Opin. Genet. Dev. 9: 461-465

30. Kinkel MD and Horton Jr WE (2003) Coordinate down-regulation of cartilage matrix gene expression in Bcl-2 deficient chondrocytes is associated with decreased SOX9 expression and decreased mRNA stability. J. Cell Biochem. 88: 941-953

31. Li L, Backer J, Wong AS, Schwanke EL, Stewart BG and Pasdar M (2003) Bcl-2 expression decreases cadherin-mediated cell-cell adhesion. J. Cell Sci. 116: 3687-3700

32. Kane DA, McFarland KN and Warga RM (2005) Mutations in half baked/Ecadherin block cell behaviors that are necessary for teleost epiboly. Development 132: 1105-1116

33. Yamamoto A, Amacher SL, Kim SH, Geissert D, Kimmel CB and De Robertis EM (1998) Zebrafish paraxial protocadherin is a downstream target of spadetail involved in morphogenesis of gastrula mesoderm. Development 125: 33893397

34. Westerfield M (2000) The Zebrafish Book (Eugene, OR: University of Oregon Press)

35. Williams JA, Barrios A, Gatchalian C, Rubin L, Wilson SW and Holder N (2000) Programmed cell death in zebrafish rohon beard neurons is influenced by TrkC1/NT-3 signaling. Dev. Biol. 226: 220-230

36. Moradi-Ameli M, Lorca T, Ficheux D, Di Pietro A and Gillet G (2002) Interaction between the antiapoptotic protein $\mathrm{Nr}-13$ and cytochrome $c$. Antagonistic effect of the $\mathrm{BH} 3$ domain of Bax. Biochemistry 41: 8540-8550

37. Aouacheria A, Ory S, Schmitt JR, Rigal D, Jurdic P and Gillet G (2002) p60(v$\mathrm{src}$ ) and serum control cell shape and apoptosis via distinct pathways in quail neuroretina cells. Oncogene 21: 1171-1186

\section{Supplementary Information accompanies the paper on Cell Death and Differentiation website (http://www.nature.com/cdd)}

